\title{
Advances in tissue engineering: Cell printing
}

\author{
David Varghese, MRCS, ${ }^{\mathrm{a}, \mathrm{b}}$ Malay Deshpande, MSc, ${ }^{\mathrm{b}}$ Tao Xu, PhD, ${ }^{\mathrm{b}}$ Priya Kesari, MSc, ${ }^{\mathrm{b}}$ Sunil Ohri, MD, FRCS(CTh), ${ }^{\mathrm{a}}$ and \\ Thomas Boland, $\mathrm{PhD}{ }^{\mathrm{b}}$ Southampton, United Kingdom, and Clemson, SC
}

T issue engineering may be defined as the science and engineering of functional tissues and organs for the replacement of diseased body parts. ${ }^{1}$ Traditionally, this has been done by the seeding of cellular material onto a suitable scaffold material to create 3-dimensional constructs. ${ }^{2}$ However there are a number of drawbacks to this technique. The degree of cellular penetration is variable and does not proceed uniformly through the scaffold. Organs consist of varied cell types in specific locations, and this is hard to replicate with this technique. Preformed, rigid scaffolds are not suitable for engineering contractile tissues, such as myocardium or vascular conduits. Perhaps the single most limiting factor with solid scaffold design is that of providing the developing structure with a vascular supply. Many of the top-down fabrication techniques that have been developed relate to the manufacture of microelectromechanical devices and are therefore unsuitable for biologic systems. It is therefore necessary to develop other strategies for assembling tissuelike constructs, a strategy that allows the creation of structures with distinct shapes and functions that are nurtured by vascular connectivity incorporating methods of vascularizing large, living, 3-dimensional tissue-engineered constructs.

Adapting bottom-up approaches to tissue engineering is a genuine challenge. Since the first application of fused deposition modeling for tissue engineering scaffolds, ${ }^{3}$ considerable effort has been focused on printing synthetic biodegradable scaffolds. ${ }^{4}$ Concurrently, a variety of rapid prototyping techniques have been developed to define macroscopically the shapes of deposited biomaterials, including photolithography, ${ }^{5}$ syringe-based gel deposition, ${ }^{6}$ and solid freeform fabrication. ${ }^{7,8}$ That these approaches have not yet led to the construction of harmonically organized complex tissues may be due to the difficulty of embedding the various cell types within the intricate designs. Our tissue engineering approach combines rapid prototyping procedures with microencapsulation to print viable freeform structures with custom-modified ink-jet printers. ${ }^{9-11}$ Inspired by developmental biology, this approach may provide the necessary cues, rules, and framework for hierarchic self-assembly. With this innovative technique, it is possible to

\footnotetext{
From the Department of Cardiothoracic Surgery, Southampton General Hospital, Southampton, United Kingdom, ${ }^{a}$ and the Department of Bioengineering, Clemson University, Clemson, SC. ${ }^{b}$

Received for publication June 4, 2004; accepted for publication June 17, 2004.

Address for reprints: Thomas Boland, PhD, 502 Rhodes, Clemson, SC 29634 (E-mail: tboland@CLEMSON.EDU).

J Thorac Cardiovasc Surg 2005;129:470-2

$0022-5223 / \$ 30.00$

Copyright $\odot 2005$ by The American Association for Thoracic Surgery

doi:10.1016/j.jtcvs.2004.06.050
}

place quickly and accurately a variety of cells layer by layer to create tissues faster than is possible with current methods.

In brief, ink-jet printers are modified by disabling the paperfeed mechanism and incorporating a stepper motor-controlled $\mathrm{z}$-axis platform. An alginate-coated frame is used as a scaffold and was mounted on this z-axis platform. The ink cartridge is filled with bovine aortic endothelial cells in culture medium (bioink). This bioink is printed layer by layer, deep to superficial, onto the scaffold, resulting in a tubular structure measuring $50 \mathrm{~mm}$ long with an outer diameter of $4 \mathrm{~mm}$.

We have printed tubes of many cell types this way, including Chinese hamster ovary cells, endothelial cells (Figure 1), smooth muscle cells, osteoblasts, and stem cells. Our initial studies focused on cellular viability, reducing bacterial contamination, and optimizing conditions of in vitro culture. We have printed dense, fused structures that can exhibit function when challenged with agonists in simple in vitro experiments. These include vasoconstriction properties of printed smooth muscle cell tubes and the potential of printed stem cells to differentiate into multiple lines, although we do not know yet how to control this differentiation.

Vital to the cell patterning procedures is the use of stable, aqueous, noncytotoxic bioinks that act as cross-linking agents delivered by the ink-jet method into a rapid prototyping chamber. There is a need to develop biomaterials that can be used as bioinks; current strategies for bioinks include natural and synthetic physical hydrogels, ${ }^{11}$ concentrated cell pellets, ${ }^{10}$ and collagen solutions. An alternative solution would be the seeding of different cell types directly onto a pliable scaffold, stacking the layers together and rolling them into tubular structures. Clearly, this technology is still in its infancy. Considerable improvements in the biomaterials used as bioinks and scaffolds will be needed before any clinical applications can be realized. Optimizing the rheologic and surface properties of the inks and designing printers optimized for these properties will improve cell density of the printed constructs and the speed at which tissues may be manufactured. Incorporation of controlled-release particles loaded with growth factors or signaling molecules into bioinks opens interesting avenues for combining cell printing with other potential therapeutic modalities.

A model of how this technique may be used for the assembly of more complex tissues is schematically shown in Figure 2. The first step is the detailed creation of a computer model of the structure to be created. The bioengineer will need to build up a layer-by-layer picture of the organ to be created by specifying the location, number, and type of cell within each layer. Once a computer-aided design file has been constructed, it can be saved and reused any number of times. The computer-aided design file is then transferred to the organ printer. This will be a purpose-built unit consisting of multiple nozzles and cartridges containing the different cell types and growth factors. The organ printer will have to be enclosed in a sterile environment in which the required 

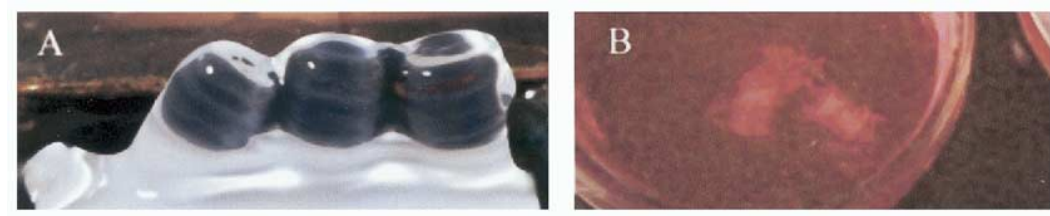

Figure 1. Macroscopic images of printed endothelial cell tubes. Cell tubes with endothelial cells as seen on day 0 immediately after printing. Different layers can be clearly seen (A). After several days of in vitro culture, cells have fused into tubes. Some cells are seeing migrating out of gels (B).

structure is built layer by layer. Cellular viability will be maintained by choosing biocompatible polymers dissolved in isotonic buffer solution or culture media and noncytotoxic cross-linkers.
The combined approach with freeform fabrication techniques aided by the inherent ability of cells and a tissue to self-assemble is an excitingly new way to construct tissues layer by layer. This

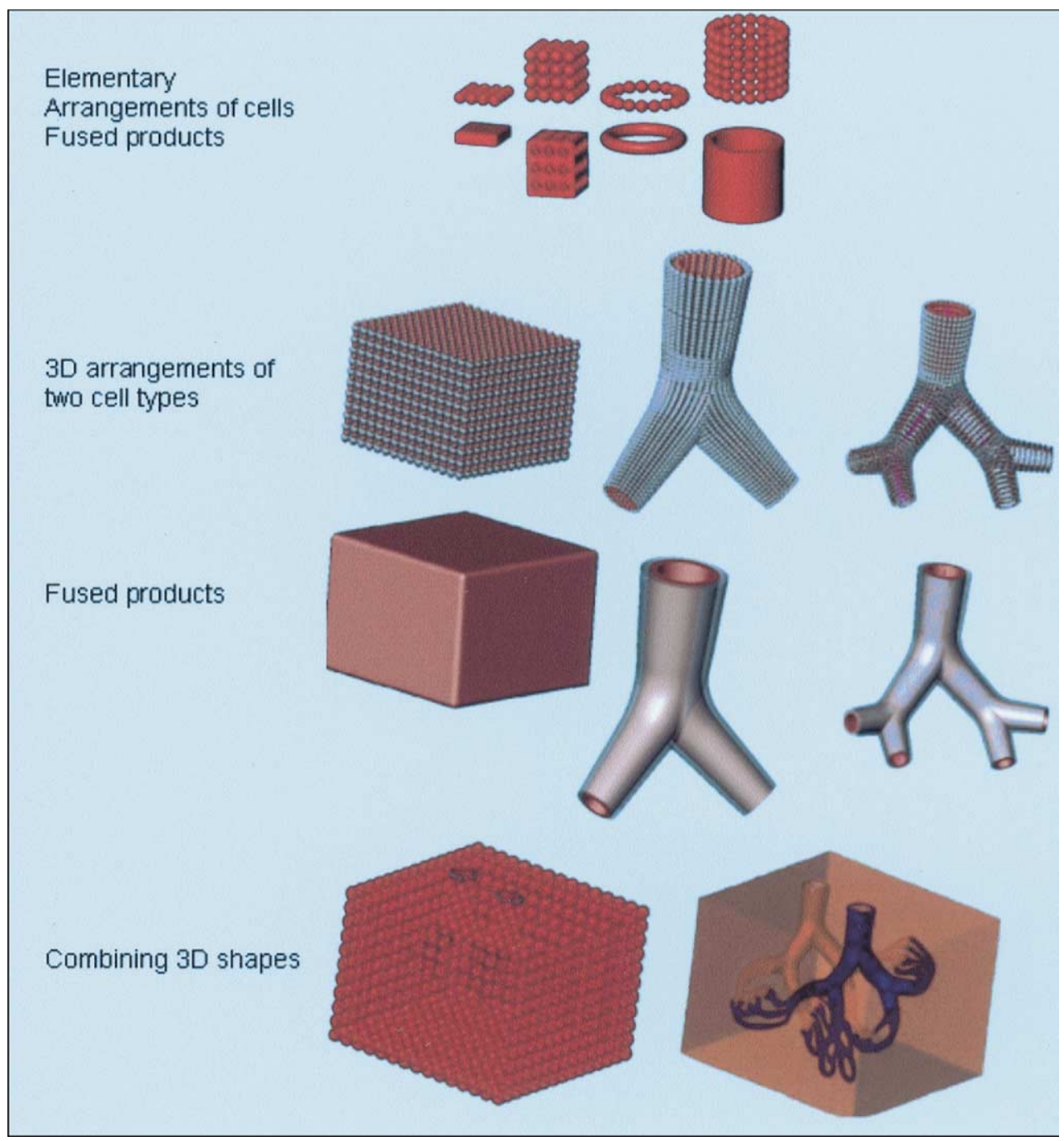

Figure 2. Diagrammatic roadmap for organ printing. Structures such as tissue cube, branching vessel, and branching vessel inside tissue cube can be printed with several different nozzles filled with cell types of interest. Cell sheets fuse to form nonvascularized cubes. Cell tubes fuse to form functional vessels. Gelling and maturation of vessels inside cube are expected to lead to vascularized tissue blocks. 
method has the potential to revolutionize the field of cardiothoracic surgery. Most of all, the continued joint efforts of developmental biologists and material scientists and engineers in the area of cell printing may lead to faster tissue construction, a cornerstone to making regenerative medicine a clinical possibility.

\section{References}

1. Sun W, Lal P. Recent development on computer aided tissue engineering-a review. Comput Methods Programs Biomed. 2002;67:85103.

2. Langer R, Vacanti JP. Tissue engineering. Science. 1993;260:920-6.

3. Hutmacher DW. Scaffolds in tissue engineering bone and cartilage. Biomaterials. 2000;21:2529-43.

4. Yang S, Leong KF, Du Z, Chua CK. The design of scaffolds for use in tissue engineering. Part II. Rapid prototyping techniques. Tissue Eng. 2002;8:1-11.
5. Vozzi G, Flaim C, Ahluwalia A, Bhatia S. Fabrication of PLGA scaffolds using soft lithography and microsyringe deposition. Biomaterials. 2003;24:2533-40.

6. Landers R, Hubner U, Schmelzeisen R, Mulhaupt R. Rapid prototyping of scaffolds derived from thermoreversible hydrogels and tailored for applications in tissue engineering. Biomaterials. 2002;23:4437-47.

7. Sachlos E, Czernuszka JT. Making tissue engineering scaffolds work. Review: the application of solid freeform fabrication technology to the production of tissue engineering scaffolds. Eur Cell Mater. 2003;5: 29-39.

8. Sachlos E, Reis N, Ainsley C, Derby B, Czernuszka JT. Novel collagen scaffolds with predefined internal morphology made by solid freeform fabrication. Biomaterials. 2003;24:1487-97.

9. Wilson WC Jr, Boland T. Cell and organ printing 1: protein and cell printers. Anat Rec. 2003;272A:491-6.

10. Mironov V, Boland T, Trusk T, Forgacs G, Markwald RR. Organ printing: computer-aided jet-based 3D tissue engineering. Trends Biotechnol. 2003;21:157-61.

11. Boland T, Mironov V, Gutowska A, Roth EA, Markwald RR. Cell and organ printing 2: fusion of cell aggregates in three-dimensional gels. Anat Rec. 2003;272A:497-502.

\title{
Selective reduction of the septolateral dimensions in functional mitral regurgitation by modified-shape ring annuloplasty
}

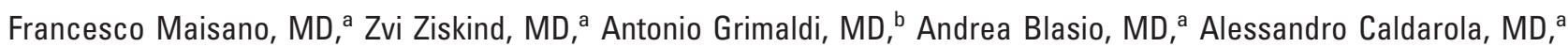 \\ Michele De Bonis, MD, ${ }^{a}$ Giovanni La Canna, MD, and Ottavio Alfieri, MD, ${ }^{\text {a }}$ Milan, Italy
}

$\mathrm{U}$ ndersized annuloplasty is the conventional surgical treatment for functional mitral regurgitation (FMR). ${ }^{1}$ The rationale of this approach is the reduction the annular diameter to force leaflet coaptation. When this technique is performed with a conventional annuloplasty prosthesis, the transverse and septolateral dimensions are proportionally reduced. However, it has been suggested that the main determinant of malcoaptation in FMR is the increase of the septolateral dimension. ${ }^{2}$ Therefore, intercommissural distance reduction is probably unnecessary, if not detrimental (it may induce anterior leaflet folding and unnecessary reduction of the total mitral valve orifice area).

We herein present an alternative method for annuloplasty, designed to selectively reduce the septolateral dimension in FMR,

\footnotetext{
From the Departments of Cardiac Surgery a and Non-invasive Diagnostic Cardiology, ${ }^{\text {b }}$ San Raffaele Foundation Institute and University Hospital, Milan, Italy.

Received for publication May 20, 2004; accepted for publication June 1, 2004.

Address for reprints: Francesco Maisano, MD, Cardiochirurgia, Istituto Scientifico Universitario, San Raffaele, Via Olgettina 60, 20132 Milano, Italy (E-mail: Francesco.maisono@hsr.it).

J Thorac Cardiovasc Surg 2005;129:472-4

$0022-5223 / \$ 30.00$

Copyright $\odot 2005$ by The American Association for Thoracic Surgery

doi:10.1016/j.jtcvs.2004.06.051
}

which is intended to improve the results of mitral repair in this challenging group of patients. ${ }^{3}$

\section{Surgical Technique and Clinical Experience}

A Carpentier rigid ring (Edwards Lifesciences Inc, Irvine, Calif) was chosen because it contains a metal core that can be reshaped. Prosthesis size was selected by measuring the intertrigonal distance and was undersized by 1 size. Before implantation, the ring was reshaped according to the sequence illustrated in Figure 1 by use of 2 tubing clamps. Shape modification created a prosthesis with the intertrigonal distance upsized by 1 size (and therefore normalized to the native valve intertrigonal dimension) and the septolateral distance undersized by 1 size (therefore, the septolateral dimension was doubly undersized), resulting in a nearly $2: 1$ intercommissural-septolateral ratio (as compared with the standard $4: 3$ ratio).

We used this approach in 14 patients with FMR between March and December 2003. There were 12 men and 2 women, with a mean age of $56 \pm 11$ years. Ten patients had ischemic and 4 had idiopathic cardiomyopathy. Preoperative mean functional class was $2.6 \pm 0.6$. FMR was severe in 12 patients and moderate in 2 (the mean regurgitation grade was $3.8 \pm 0.6$ ). The mean coaptation depth was $1.09 \pm 0.44 \mathrm{~cm}$ (range, $0.6-2.0 \mathrm{~cm}$ ) and exceeded $1 \mathrm{~cm}$ in 6 patients. ${ }^{4} \mathrm{~A}$ complex regurgitant jet (eccentric or multiple) was detected in 9 patients. ${ }^{5}$ The mean tenting area was $2.1 \pm 0.82$ $\mathrm{cm}^{2}$ (range, $1.3-4 \mathrm{~cm}^{2}$ ). The mean size of the implanted Carpentier ring was $29.7 \pm 2.6$. Associated procedures included the edge-toedge procedure (12 patients), coronary revascularization (10 pa- 